\title{
Serious, Minor, and Non-Delinquents in Early Adolescence: The Impact of Cumulative Risk and Promotive Factors. The TRAILS Study
}

\author{
André M. van der Laan - René Veenstra • \\ Stefan Bogaerts • Frank C. Verhulst • Johan Ormel
}

Published online: 3 December 2009

(C) The Author(s) 2009. This article is published with open access at Springerlink.com

\begin{abstract}
This study uses a social-ecological approach to the development of delinquency. The authors emphasize that a balance between eliminating risk and enhancing protection across domains is essential in reducing problems and promoting competence. The cumulative risk and promotive effects of temperament, family and school
\end{abstract}

This research is part of the TRacking Adolescents' Individual Lives Survey (TRAILS). Participating centers of TRAILS include various departments of the University Medical Center and University of Groningen, the Erasmus University Medical Center Rotterdam, the University of Utrecht, the Radboud Medical Center Nijmegen, and the Trimbos Institute, all in the Netherlands. Principal investigators are Prof. Dr. J. Ormel (University Medical Center Groningen) and Prof. Dr. F.C. Verhulst (Erasmus University Medical Center). TRAILS has been financially supported by various grants from the Netherlands Organization for Scientific Research NWO (Medical Research Council program grant GB-MW 940-38-011; ZonMW Brainpower grant 100-001-004; ZonMw Risk Behavior and Dependence grant 6060600-97-118; ZonMw Culture and Health grant 261-98-710; Social Sciences Council medium-sized investment grant GB-MaGW 480-01006 and project grants GB-MaGW 457-03-018 and GB-MaGW 45204-314; NWO large-sized investment grant 175.010.2003.005); the Sophia Foundation for Medical Research (projects 301 and 393), the Dutch Ministry of Justice (WODC), and the participating universities. We are grateful to all adolescents, their parents and teachers who participated in this research and to everyone who worked on this project and made it possible. We want to thank the editor and the anonymous reviewers for their helpful comments on previous versions of the manuscript.

A. M. van der Laan $(\bowtie)$

Crime, Prevention and Sanctions division,

WODC, Ministry of Justice,

PO BOX 20301, 2500 EH The Hague, the Netherlands

e-mail: a.m.van.der.laan@minjus.nl

\section{R. Veenstra}

Department of Sociology, Interuniversity Center for Social Science Theory and Methodology (ICS), University of Groningen, Groningen, the Netherlands factors in preadolescence were examined on different groups of delinquents (based on self-report) in early adolescence. Data from the first two waves of the TRAILS study $(N=2,230)$ were used. The results provide evidence for a compensatory model that assumes main effects of risk and promotive factors on problem behavior. Accumulation of risks in preadolescence promoted being a serious delinquent in early adolescence, with the strongest effects for temperament. Accumulation of promotive effects decreased being a delinquent and supported being a nondelinquent. Furthermore, evidence is found for a counterbalancing effect of cumulative promotive and risk factors. Exposure to more promotive domains in the relative absence of risk domains decreased the percentage of serious delinquents. Our results did not support a protective model. Implications for prevention and intervention are discussed.

Keywords Delinquency · Risk factors · Promotive factors · Protective factors $\cdot$ Accumulation of factors $\cdot$ Compensatory model $\cdot$ Protective model

A variety of factors in childhood increase the probability of serious delinquency in adolescence (e.g., Farrington 2003; Lipsey and Derzon 1998; Loeber et al. 2008). Temperamental risks include impulsivity and risk taking. In the

R. Veenstra

Department of Psychology, University of Turku,

Turku, Finland

S. Bogaerts

Department of Social Science and Law, University of Tilburg, Tilburg, the Netherlands

S. Bogaerts

Department of Law, Catholic University Louvain,

Louvain, Belgium 
family domain, factors such as poor parental bonding, insecure attachment, poor parenting practices, parental neglect, family stress, and a low SES have been found to be predictors of serious delinquency (Henry et al. 1996; Hoeve et al. 2008, 2009; Sentse et al. 2009). Low attachment to school and poor academic performance are examples of risks related to the school domain (Smith 2006; Loeber et al. 2008; Valois et al. 2002).

However, not all children become serious delinquents. According to resilience theory at least two processes can explain this (Fergusson et al. 2007; Garmezy et al. 1984; Luthar et al. 2000; Rutter 1987, 2003). The first one is a protection process. This assumes that children exposed to risks also have factors that protect them not to become a serious delinquent. The second explanation concerns the compensatory process which assumes that some factors reduce the overall exposure to risk.

Based on resilience theory (Garmezy et al. 1984; Luthar et al. 2000; Rutter 1987, 2003), we will examine a compensatory model suggesting that some factors, labeled as promotive factors (Farrington et al. 2008; Sameroff et al. 1998; Stouthamer-Loeber et al. 2002), decrease problem behavior directly, regardless of risk (Garmezy et al. 1984; Luthar et al. 2000). For example, bonding with conventional parents decreases delinquency (Dekovic 1999; Stouthamer-Loeber et al. 2002). Promotive factors are associated with better outcomes under all conditions. Promotive factors also enhance healthy development (Fergus and Zimmerman 2005; Ostaszewski and Zimmerman 2006) and prosocial behavior (Stouthamer-Loeber et al. 2002; Vanderbilt-Adriance and Shaw 2008a).

Resilience research also suggested to take protective factors into account (Herrenkohl et al. 2003; Pollard et al. 1999; Rutter 1987, 2003). Studies on high risk groups found protective factors to modify the effects of risks on delinquency (e.g., Herrenkohl et al. 2003; Rutter 1987; 2003), known as the protective model (Garmezy et al. 1984; Rutter 1987). In a high risk population of youth, factors that protect against serious delinquency are e.g., an easy temperament or high IQ (Condly 2006; Vanderbilt-Adriance and Shaw 2008a), or good family management (Condly 2006; Herrenkohl et al. 2003; Vanderbilt-Adriance and Shaw 2008a).

The distinction between risk, protective and promotive factors is an issue of debate amongst scholars (e.g.

\section{F. C. Verhulst}

Department of Child and Adolescent Psychiatry, Erasmus Medical Center Rotterdam,

Rotterdam, the Netherlands

\section{J. Ormel}

Department of Psychiatry, Graduate School of Behavioral and Cognitive Neurosciences, and Graduate School for Experimental Psychopathology, University Medical Center Groningen,

Groningen, the Netherlands
Farrington et al. 2008; Fergusson and Lynskey 1996, Fergusson et al. 2007; Garmezy et al. 1984; Luthar et al. 2000; Rutter 1987, 2003; Sameroff et al. 1998; StouthamerLoeber et al. 1993, 2002). One part of the debate concerns the question whether factors are unipolar or bipolar. Some argue that factors have unipolar effects. They see factors that decrease problem behavior, so-called protective factors, as unique factors that are not the opposite of risk factors (e.g. Herrenkohl et al. 2003; Pollard et al. 1999; Rutter 1987, 2003). Others state that factors can have bipolar effects, with risk and promotive effects being the ends of one continuum (e.g. Farrington et al. 2008; Sameroff et al. 1998; Stouthamer-Loeber et al. 1993, 2002). These scholars do not assume the effects of factors a priori, but state that these should be empirically based (Farrington et al. 2008). Viewed in this way a factor can act for one person as a risk, for another person as a promotive factor, and for a third as a neutral factor (Stouthamer-Loeber et al. 2002).

Another part of this debate concerns the mechanisms behind promotive and protective factors. Some researchers (Farrington et al. 2008; Loeber et al. 2008; Sameroff et al. 1998; Stouthamer-Loeber et al. 2002) conceptualize promotive factors as factors that lower the probability of problem behavior, regardless of risk. Protective factors are conceptualized as factors that moderate the effects of risk on problem behavior (Fergusson and Lynskey 1996; Pollard et al. 1999; Rutter 1987, 2003). These factors lower the probability of problem behavior only in the face of adversity (Rutter 1987). Protective factors can be seen as a subcategory of promotive factors. Protective factors are those factors that reduce the effects of risk factors on problem behavior (Farrington et al. 2008).

Studies on delinquency from a social-ecological perspective revealed that exposure to an accumulation of risks in multiple domains, rather than a single domain, increases the likelihood of later negative outcomes (see Loeber et al. 2008; Stouthamer-Loeber et al. 2002). With regard to promotive effects, studies suggest a similar pattern: an accumulation of promotive effects lowers the probability of problems (e.g., Dekovic 1999; Farrington et al. 2008; Sameroff et al. 1998). Luthar et al. (2000) emphasize that a balance between eliminating risk and enhancing promotive factors across domains of functioning is essential in reducing problems and promoting competence (Sameroff et al. 1998; Stouthamer-Loeber et al. 2002). For example, Stouthamer-Loeber et al. (2002) found a counter-balancing effect of risk and promotive factors across domains on persistent delinquents. The more risk factors and the less promotive factors increased the likelihood of being a persistent delinquent. In a Dutch cross-sectional study the inverse was found for non-delinquents: the more promotive factors and the less risk factors related to a higher percentage of non-delinquents (Van der Laan and Blom 2006). However, few studies have examined the longitudi- 
nal effects of cumulative risk and promotive factors across domains simultaneously (Vanderbilt-Adriance and Shaw 2008a, 2008b) in a general population of preadolescents on their future delinquent behavior.

We examined an accumulation of risk and promotive effects of factors across domains in preadolescence on delinquency in early adolescence from a developmental social-ecological perspective (see Loeber et al. 2008). The most prominent factors related to (serious) delinquency in early adolescence are individual, family, and school factors (Loeber et al. 2008).

Our study distinguishes from previous research in several ways. First, we investigate which factors have bipolar and which have unipolar effects instead of assuming these a priori. Second, we test all three models described in the literature: the risk, compensatory, and protective model. Previous studies only focus on one or two of these models. Third, studies on compensation or protection mostly focused on groups at risk, e.g. low-SES youth, males, or children who showed problem behavior. We examine these models longitudinally using a general population sample of preadolescents. Fourth, whereas most studies focused on risk and promotive effects on only serious delinquents, we also pay attention to the effects on minor and non-delinquents.

Our research question was: "What are the effects of an accumulation of risk and promotive effects in the individual (temperament), family (parenting practices, stress), and school (performance and social well-being) domains measured in preadolescence (T1) on a group of nondelinquents, minor delinquents, and serious delinquents in early adolescence (T2)?" We expected an accumulation of risk factors to increase the likelihood of being a minor or a serious delinquent (risk model). Furthermore, we expected an accumulation of promotive factors to decrease the likelihood of being a minor or a serious delinquent and to increase the likelihood of being a non-delinquent (compensatory model). In addition, we did not only expect direct effects of promotive factors but we also expected that promotive factors modify the relation of an accumulation of risks on the probability of being a serious delinquent (protective model), referring to risk-buffering effects of promotive factors.

\section{Method}

Sample

The TRacking Adolescents' Individual Lives Survey (TRAILS) is a prospective cohort study of Dutch preadolescents who will be measured biennially until they are at least 25 years old. The present study involved the first two waves of TRAILS, which started in 2001. TRAILS is designed to chart and explain the development of mental health and social development from preadolescence into adulthood. The TRAILS target sample comprised preadolescents living in five municipalities in the North of the Netherlands, including both urban and rural areas. The sample and sample selection at $\mathrm{T} 1$ has been described elsewhere more extensively (De Winter et al. 2005; Oldehinkel et al. 2004).

Of all children approached for enrolment in the study (selected by the municipalities and attending primary schools that were willing to participate: $N=3,145$ children from 122 schools; response of schools $90.4 \%$ ), $6.7 \%$ were excluded because of incapability or language problems. Of the remaining 2,935 children, $76.0 \%$ were enrolled in the study, yielding $N=2,230$ (both child and parent agreed to participate; mean age of child $11.09, S D=0.55 ; 50.8 \%$ girls; $10.3 \%$ of the children had at least one parent born in a nonwestern country; parents'; $32.6 \%$ of children had parents with a low educational level, at maximum a certificate from a lower track of secondary education). No non-response bias was found in our study for the estimation of the prevalence rates of psychopathology, including antisocial behavior. However, boys, children from lower social strata, and children with worse school performance were somewhat more likely to belong to the non-response group (De Winter et al. 2005). Of the 2,230 baseline participants, $96.4 \%(N=2,149,51.0 \%$ girls $)$ participated in T2. Mean age at $\mathrm{T} 2$ was 13.56 years $(S D=0.53)$. At $\mathrm{T} 1$ the respondents mainly attended the last 2 years of primary education. At $\mathrm{T} 2$ the vast majority of the respondents attended the first 2 years of secondary education.

Well-trained interviewers visited one of the parents (preferably the mother, 95.6\%) at their homes to administer an interview covering a wide range of topics, including the child's developmental history and somatic health, parental psychopathology, and care utilization. The parent was also asked to fill out a questionnaire. The children filled out questionnaires at school, in the class, under the supervision of one or more TRAILS assistants. Teachers were asked to fill out a brief questionnaire for all TRAILS children in their class. The measures used in the present study are described more extensively below.

\section{Measures}

Delinquency (T1 and T2)

The delinquency scale consisted of 23 items adapted from the 'self-reported delinquency scale' of Moffitt and Silva (1988). Only items that directly referred to criminal offenses were included. Excluded were items like cigarette 
smoking, marijuana use, being expelled from school, running away from home, and having contact with the police in general (because none of these behaviors is criminal in the Netherlands). Children were asked if they had committed criminal offenses, and how often (never; once; 2-3 times; 4-6 times; 7 times or more). The items were embedded in a cluster of items with an explicit reference period of 6 months.

To construct the delinquency scale, we used information about diversity, seriousness, and frequency of the offenses (Piquero et al. 2003). We used 23 items which referred to a variety of offense types, such as property and violent offenses. Next, the offenses were divided into non-serious and serious. Of the 23 items, 16 were labeled as nonserious. Non-serious offenses included 'vandalism', and 'theft below 10 euros'. Serious offenses included 'beating a person seriously so that $\mathrm{s} / \mathrm{he}$ needs to go to hospital' and 'robbery'. Non-serious offenses were coded 1 and serious offenses were scored 2. For each offense we multiplied the seriousness and frequency scores. Finally, by adding the multiplicative scores we computed a delinquency sum score (23-items, $\alpha=0.85$; T1 range $0-49, M=5.62, S D=6.11$; T2 range $=0-50 ; M=4.83, S D=6.16$ ). At both waves, girls had significantly lower scores than boys (T1: $t(1729.6)=-14.9$, $p<0.01 ; \mathrm{T} 2: t(1743.5)=-10.0, p<0.01)$.

To examine construct validity we conducted correlations between the mean of the combined YSR, CBCL, and TCP delinquency and aggression scales (Achenbach 1987, 1991a, b; Verhulst and Achenbach 1995). In general, positive correlations with delinquency (T1: $r=0.58, p<$
0.01; T2: $r=0.54, p<0.01$ ), and with aggression (T1: $r=$ $0.51, p<0.01 ; \mathrm{T} 2: r=0.47, p<0.01)$ were found at both waves.

We then distinguished three groups on the delinquency sum score: a group of non-delinquents (the lower quartile; none of these children committed an offense), a group of serious delinquents (the upper decile), and a group of minor delinquents (in between the 25th and 90th percentiles), see Table 1 . The three groups differed significantly $(p<0.01)$ with regard to gender, SES, diversity and seriousness of offenses, and the mean scores on the combined and $z$ standardized aggression and delinquency scales of the YSR, CBCL, and TCP. The percentage of males in the group of non-delinquents was $38.3 \%$; in the group of minor delinquents, $48.8 \%$; and in the group of serious delinquents, $72.6 \%$ (overall $\left.\chi^{2}(2)=62.56 ; p<0.01\right)$.

\section{Individual (T1)}

Individual factors were assessed using temperament scales. We used the parent version of the Early Adolescent Temperament Questionnaire-Revised (EATQ-R; Putnam et al. 2001). This is a 62-item questionnaire based on the temperament model developed by Rothbart et al. (2000). We used four scales. Effortful control is the capacity to voluntarily regulate behavior and attention (11 items, $\alpha=$ 0.86). Shyness measures behavioral inhibition in relation to novelty and challenge, especially social (four items, $\alpha=$ 0.84). High-Intensity Pleasure or surgency reflects the pleasure derived from activities involving high intensity or

Table 1 Characteristics of Non-, Minor, and Serious Delinquents

\begin{tabular}{|c|c|c|c|c|c|c|c|}
\hline & \multirow{2}{*}{\multicolumn{2}{|c|}{$\begin{array}{l}\text { Non-delinquents } \\
N=465\end{array}$}} & \multirow{2}{*}{\multicolumn{2}{|c|}{$\begin{array}{l}\text { Minor delinquents } \\
N=1419\end{array}$}} & \multicolumn{2}{|c|}{ Serious delinquents } & \multirow[t]{4}{*}{ Differences between groups } \\
\hline & & & & & $N=201$ & & \\
\hline & \multicolumn{2}{|c|}{$(22.3 \%)$} & \multicolumn{2}{|c|}{$(68.1 \%)$} & \multicolumn{2}{|l|}{$(9.6 \%)$} & \\
\hline & M & $(\mathrm{SD})$ & M & $(\mathrm{SD})$ & M & (SD) & \\
\hline \multicolumn{8}{|c|}{ Background characteristics (T1) } \\
\hline Socio-economic status & 2.11 & $(0.71)^{\mathrm{a}}$ & 2.02 & $(0.70)^{\mathrm{b}}$ & 1.78 & $(0.72)^{\mathrm{c}}$ & $F(2,2051)=14.94 * *$ \\
\hline Age in years & 11.05 & $(0.55)^{\mathrm{a}}$ & 11.09 & $(0.55)^{\mathrm{a}}$ & 11.12 & $(0.50)^{\mathrm{b}}$ & $F(2,2082)=3.91 *$ \\
\hline \multicolumn{8}{|l|}{ Offenses (T2) } \\
\hline Diversity of offenses & 0.00 & $(0.00)^{\mathrm{a}}$ & 3.18 & $(2.05)^{\mathrm{b}}$ & 11.37 & $(3.04)^{\mathrm{c}}$ & $F(2,2080)=2412.34 * *$ \\
\hline Non-serious offenses & 0.00 & $(0.00)^{\mathrm{a}}$ & 3.07 & $(1.97)^{\mathrm{b}}$ & 9.71 & $(2.35)^{\mathrm{c}}$ & $F(2,2080)=2084.41 * *$ \\
\hline Serious offenses & 0.00 & $(0.00)^{\mathrm{a}}$ & 0.10 & $(0.34)^{\mathrm{b}}$ & 1.66 & $(1.56)^{\mathrm{c}}$ & $F(2,2080)=724.73^{* *}$ \\
\hline \multicolumn{8}{|c|}{ YSR, CBCL, TCP scales (T2) } \\
\hline Aggression $\mathrm{T} 2$ & -0.40 & $(0.52)^{\mathrm{a}}$ & 0.01 & $(0.70)^{\mathrm{b}}$ & 0.85 & $(1.00)^{\mathrm{c}}$ & $F(2,2008)=216.96^{* *}$ \\
\hline Delinquency T2 & -0.41 & $(0.42)^{\mathrm{a}}$ & -0.02 & $(0.66)^{\mathrm{b}}$ & 1.07 & $(1.18)^{\mathrm{c}}$ & $F(2,2008)=314.73 * *$ \\
\hline
\end{tabular}

Means in the same row that do not share superscripts differ at $p<0.05$ in a Games Howel Post hoc comparison. Aggression and delinquency are mean scores on the combined scales of the z-standardized YSR, CBCL and TCP scales

$* p<0.05 ; * * p<0.01$ 
novelty (six items, $\alpha=0.77$ ). Frustration measures the negative affect related to interruption of ongoing tasks or goal blocking (five items, $\alpha=0.74$ ). The properties of these scales are described by Oldehinkel et al. (2004).

\section{Family (T1)}

Family factors were assessed using five scales. Three of those reflected children's perceptions of their parents' methods of child rearing. The items were adopted from the shorter version of the Egna Minnen Beträffande Uppfostran (My Memories of Upbringing) for Children [EMBU-C] (Markus et al. 2003; Veenstra et al. 2006). Children could rate the EMBU-C as $1=$ no, never, $2=$ yes, sometimes, $3=$ yes, often, $4=$ yes, almost always. Each item was asked for both the father and the mother. We used three scales. Emotional warmth measures giving special attention, praise for approved behavior, unconditional love, and being supportive and affectionately demonstrative ( 18 items, $\alpha=0.91$ for both fathers and mothers). Overprotection is characterized by fearfulness and anxiety for the child's safety, guilt engendering, and intrusiveness ( 12 items, $\alpha=0.70$ for fathers, and $\alpha=0.71$ for mothers). Rejection is characterized by hostility, punishment (physical or otherwise, abusive or otherwise), derogation, and blaming of subject (12 items, $\alpha=0.84$ for fathers, and $\alpha=0.83$ for mothers). The answers for both parents were highly correlated $(r \mathrm{~s}=0.79$ for emotional warmth, 0.67 for rejection, and 0.81 for overprotection), so we combined them using mean scores. Markus et al. (2003) have reported on the validity of the EMBU-C.

The two remaining family factors concern family functioning and family stress, both as perceived by the parent. To measure family functioning we used the General Functioning scale of the McMaster Family Assessment Device (Epstein et al. 1983). This scale is used to assess the overall health/ pathology of the family. A low score on the scale indicates a healthy family climate; a high score represents a dysfunctional family climate (12-items, $\alpha=0.85)$. Parental stress was measured using a short form of the Parental Stress Index (Burke and Abidin 1980), a questionnaire used to measure the magnitude of stress in the parent-child system. The items provide an indication of parents' dissatisfaction regarding the interactions with their children and the degree to which parents find their child's behavior unacceptable; and parents' perceptions of their children's self-regulatory abilities are measured (24-items, $\alpha=0.94)$. A high score on the scale indicates a high level of stress experienced by the primary caregiver in relation to the child.

\section{School (T1)}

To measure the functioning of the child at school we used three indicators. Academic performance is a scale measur- ing the intellectual performance of the child at school as perceived by the teacher (rating on a 5-points Likert scale (fully disagree-fully agree), five items, $\alpha=0.85$ ). Next, the perceived social well-being of children in class was measured using two scales adapted from the Social Production Functions questionnaire (see Ormel et al. 1997; Ormel 2002). Social well-being toward teacher measures affection and behavioral confirmation toward the teacher (rating on a 5-points Likert scale (never-always), 11 items, $\alpha=0.89$ ). Social well-being toward classmates measures perceived affection from classmates, and behavioral confirmation toward classmates (rating on a 5-point Likert scale (never-always), 8 -items, $\alpha=0.90$ ). Both scales were based on child reports.

\section{Controls (T1)}

Gender and family SES are highly predictive childhood factors for serious delinquency in adolescence (Farrington 2003). For this reason, we used gender, and family SES, both measured at $\mathrm{T} 1$, as controls in the multivariate analyses. The sample consisted of $50.8 \%$ girls and $49.2 \%$ boys. The TRAILS database contains various variables for SES: income level, educational level of both parents, and occupational level of each parent, using the International Standard Classification for Occupations (Ganzeboom and Treiman 1996). SES was measured as the average of the five items (standardized). The SES scale captured $61.2 \%$ of the variance in the five items and had an internal consistency of 0.84 . We distinguished three SES groups: low-level SES (1 SD below the mean), high-level SES (1 $\mathrm{SD}$ above the mean), and an intermediate SES group.

\section{Analyses}

For each domain we computed cumulative risk and promotive sum scores. Before creating sum scores, we determined whether single variables in preadolescence (T1) had significant risk or promotive effects on delinquency in early adolescence (T2). We conceptualized risk and promotive effects as the ends of a distribution of the same variable. Depending on the individuals' scores on the distribution of the variable, variables can have a risk effect for one, a promotive effect for another, and no effect for a third person (Stouthamer-Loeber et al. 1993, 2002). To capture possible risk and promotive effects, we created a dummy variable with a low (below the 25 th percentile) and a high score (above the 75th percentile) for each variable. The middle half of the sample is used as a reference category.

By forming a measure reflecting a risk or a promotive effect, the interpretation of the results are simplified without substantial loss of information compared to continuous 
variables. Farrington and Loeber (2000) have shown that this way of categorizing has little effect on conclusions about the relative importance of explanatory variables. Additionally, trichotomizing variables makes it possible to examine non normal distributed variables and non linear relationships which are often present in criminological research. Importantly, this procedure makes it clear which end of the distribution of a variable can be used in the cumulative scores. Trichotomous data make it easy to identify individuals affected by multiple risk/promotive factors, and to construct cumulative risk/promotive scores across domains (see also Farrington et al. 2008; Stouthamer-Loeber et al. 2002; Van der Laan and Blom 2006). Only variables with significant risk or promotive effects were used (two-tailed tests). Based on the significant risk and promotive effects in the univariate analyses, we calculated cumulative risk and promotive scales for each domain.

The analyses show the relative effect of each cumulative risk or promotive score on the three groups of delinquents. According to Stouthamer-Loeber et al. (2002) promotive effects counterbalance the effects of risks across domains. This counter-balancing effect is only found longitudinal in a sample of inner-city males (Stouthamer-Loeber et al. 2002) or cross sectional (Van der Laan and Bloom 2006). We examined counter-balancing effects of promotive factors on risks across the three domains by calculating an overall cumulative promotive-risk scale. We calculated this overall scale in the same way as done by StouthamerLoeber et al. (2002). In each domain we added the risk effects and subtracted the promotive effects found in the univariate analyses. Each domain score was trichotomized into a promotive score (below the 25th percentile; score -1 ), a risk score (above the 75th percentile; score 1), and a neutral score (in between; score 0 ). We then summed the three domain scores into an overall cumulative promotiverisk scale, with a low score indicating promotive effects on all three domains and a high score risk effects on all three domains (range from -3 to $3, M=-0.29, S D=1.09$ ).

We used multinomial logistic regression to examine the effects of independent variables on non-delinquents, minor delinquents, and serious delinquents, a categorical outcome. To interpret the outcomes of the multinomial logistic regression we used marginal effects (Borooah 2002; Liao 1994). The marginal effect for a dummy variable is the difference between being in category 1 and being in category 0 . The marginal effect for a continuous variable is the effect of a variable on an outcome with one point of increase in the score of the variable.

In order to examine the impact of cumulative promotive effects relative to that of cumulative risk effects, we used a stepwise Multinomial Logistic Model (MNLM) and assessed the improvement using the change in $\chi^{2}$. The $\chi^{2}$ has shown to be a strong goodness of fit index in logistic models (Hosmer et al. 1997). The compensatory model is tested in multinomial logistic regression analyses by examining the main effects of the cumulative promotive factors next to the cumulative risk factors, whereas the protective model is tested by including interaction terms (by centering the variables; Aiken and West 1992).

Our baseline model included the controls gender and SES. In a next step, we entered a risk model, followed by a compensatory model, and a protective model. We ended by controlling for previous delinquency. This provides information about whether cumulative risk and promotive factors produce change in delinquency over a 2,5-year time interval.

We used corrected-item-mean (CIM) imputation to handle missing data at the item level (Huisman 2000). At the scale level, we did multiple imputation using the MICE method of multivariate imputation (Allison 2002; Royston 2004). In these procedures it is assumed that the data are missing at random. As a result of the imputation we were able to use 2,085 cases in our analyses.

\section{Results}

\section{Univariate Associations}

We examined univariate associations of the independent variables at $\mathrm{T} 1$ with the delinquent groups at $\mathrm{T} 2$ (see Table 2). As can be observed from the overall $\chi^{2}$, all variables were significantly related to the three groups at $p<0.01$, except emotional warmth $\left(\chi^{2}(4,2,085)=11.0 ; p=0.03\right)$ and social well-being toward classmates $\left(\chi^{2}(4,2,085)=11.1 ; p=0.03\right)$. These variables were excluded from further analyses.

In Table 2 we also report marginal effects for each delinquent group. The effects are labeled as risk or promotive in the far right column. In the domain of temperament, risk effects were found for low effortful control, high surgency, and high frustration. Promotive effects were found for high effortful control, high shyness, and low surgency. Low effortful control, for example, increased the likelihood of belonging to the group of serious delinquents by $5.6 \%$ points $(p<0.01)$. High effortful control increased the likelihood of being a non-delinquent by $6.3 \%$ points $(p<0.01)$ and decreased the probability of being a serious delinquent by $3.1 \%$ points $(p<0.10)$. In Table 2, the sum of the effects in each row is zero, which is typical of marginal effects.

With regard to family variables risk effects were found for high rejection, dysfunctional family functioning, and high parental stress. Low overprotection, healthy family functioning, and low parental stress showed promotive effects. Low rejection and dysfunctional family functioning 
Table 2 Univariate Associations of Temperament, Family and School at T1 with Being a Non-, Minor, or Serious Delinquent at T2 (Overall $\chi^{2}$, Marginal Effects (S.E.)), $N=2,085$

\begin{tabular}{|c|c|c|c|c|c|c|}
\hline \multirow[t]{2}{*}{ Variable } & \multirow[t]{2}{*}{ Overall $\chi^{2}$} & \multirow[t]{2}{*}{$p$} & \multicolumn{3}{|c|}{ Marginal effects (S.E.) } & \multirow[t]{2}{*}{ Effect } \\
\hline & & & Non-delinquents & Minor delinquents & Serious delinquents & \\
\hline \multicolumn{7}{|l|}{ Temperament } \\
\hline \multicolumn{7}{|c|}{ Effortful control $^{\mathrm{a}}$} \\
\hline Low & 29.43 & $<0.01$ & $-3.4(2.3)$ & $-2.2(2.5)$ & $5.6(1.8)^{* * *}$ & Risk \\
\hline High & & & $6.3(2.5)^{* * *}$ & $-3.2(2.7)$ & $-3.1(1.6)^{*}$ & Promotive \\
\hline \multicolumn{7}{|l|}{ Shyness ${ }^{\mathrm{a}}$} \\
\hline Low & 17.55 & $<0.01$ & $-0.2(2.5)$ & $-1.5(2.8)$ & $1.7(1.8)$ & - \\
\hline High & & & $8.2(2.5)^{* * *}$ & $-6.1(2.8)^{* *}$ & $-2.0(1.8)$ & Promotive \\
\hline \multicolumn{7}{|l|}{ Surgency $^{\mathrm{a}}$} \\
\hline Low & 38.35 & $<0.01$ & $6.5(2.4)^{* * *}$ & $-1.7(2.6)$ & $-4.8(1.4)^{* * *}$ & Promotive \\
\hline High & & & $-4.2(2.4)^{*}$ & $0.7(2.7)$ & $3.5(1.7)^{* *}$ & Risk \\
\hline \multicolumn{7}{|c|}{ Frustration $^{\mathrm{a}}$} \\
\hline Low & 23.53 & $<0.01$ & $3.3(2.4)$ & $-1.1(2.6)$ & $-2.2(1.7)$ & - \\
\hline High & & & $-4.3(2.4)^{*}$ & $-2.0(2.8)$ & $6.4(2.1)^{* * *}$ & Risk \\
\hline \multicolumn{7}{|c|}{ Family environment } \\
\hline \multicolumn{7}{|c|}{ Emotional warmth ${ }^{\mathrm{b}}$} \\
\hline Low & 11.02 & 0.03 & - & - & - & - \\
\hline High & & & - & - & - & - \\
\hline \multicolumn{7}{|c|}{ Overprotection $^{\mathrm{b}}$} \\
\hline Low & 19.59 & $<0.01$ & $8.0(2.5)^{* * *}$ & $-3.5(2.7)$ & $-4.5(1.4)^{* * *}$ & Promotive \\
\hline High & & & $1.5(2.3)$ & $-2.8(2.5)$ & $1.4(1.5)$ & - \\
\hline \multicolumn{7}{|l|}{ Rejection $^{\mathrm{b}}$} \\
\hline Low & 26.58 & $<0.01$ & $4.0(2.2)^{*}$ & $-3.2(2.5)$ & $-0.7(1.6)$ & Promotive \\
\hline High & & & $-8.6(2.1)^{* * *}$ & $6.0(2.5)^{* * *}$ & $2.6(1.8)$ & Risk \\
\hline \multicolumn{7}{|c|}{ Family functioning $^{\mathrm{a}}$} \\
\hline Healthy & 16.32 & $<0.01$ & $7.6(2.4)^{* * *}$ & $-5.5(2.8)^{* *}$ & $-2.1(1.8)$ & Promotive \\
\hline Dysfunct & & & $-2.8(2.5)$ & $-0.6(3.0)$ & $3.4(2.1)^{*}$ & Risk \\
\hline \multicolumn{7}{|c|}{ Parental stress ${ }^{\mathrm{a}}$} \\
\hline Low & 38.93 & $<0.01$ & $5.4(2.2)^{* * *}$ & $-2.8(2.5)$ & $-2.7(1.6)^{*}$ & Promotive \\
\hline High & & & $-7.0(2.3)^{* * *}$ & $1.8(2.7)$ & $5.2(1.9)^{* * *}$ & Risk \\
\hline \multicolumn{7}{|c|}{ School environment } \\
\hline \multicolumn{7}{|c|}{ Academic performance ${ }^{c}$} \\
\hline Low & 35.82 & $<0.01$ & $-6.1(2.2)^{* * *}$ & $1.8(2.5)$ & $4.3(1.7)^{* * *}$ & Risk \\
\hline High & & & $1.4(2.4)$ & $3.5(2.6)$ & $-4.9(1.5)^{* * *}$ & Promotive \\
\hline \multicolumn{7}{|c|}{ Social wellbeing teacher ${ }^{\mathrm{b}}$} \\
\hline Low & 27.46 & $<0.01$ & $-6.0(2.2)^{* * *}$ & $-0.8(2.7)$ & $6.9(2.0)^{* * *}$ & Risk \\
\hline High & & & $1.7(2.2)$ & $-0.3(2.5)$ & $-1.4(1.6)$ & - \\
\hline \multicolumn{7}{|c|}{ Social well-being classmates ${ }^{\mathrm{b}}$} \\
\hline Low & 11.1 & 0.03 & - & - & - & - \\
\hline High & & & - & - & - & - \\
\hline
\end{tabular}

The overall $\chi^{2}$ is calculated for each variable separately

${ }^{\text {a }}$ Parent report

${ }^{\mathrm{b}}$ Child report

${ }^{\mathrm{c}}$ Teacher report

${ }^{*} p<0.10 ; * * p<0.05 ; * * * p<0.01$ (two-tailed) 
only showed marginally significant $(p<0.10)$ effects on non-delinquents and serious delinquents.

School variables with risk effects were low academic performance and low social well-being toward the teacher. High academic performance was the only school variable with a promotive effect.

\section{Accumulation of Risk and Promotive Effects}

Next, we examined the impact of cumulative risk and promotive effects on the three groups of delinquents. The cumulative risk scale for temperament, for example, included low effortful control, high surgency, and high frustration (referring to the three temperamental risk factors from Table 2). A higher score indicated a more difficult temperament (range $=0-3, M=0.70, S D=0.80$ ). The cumulative promotive scale for temperament included high effortful control, high shyness, and low surgency, with a higher score indicating an easier temperament (range $=0-3$, $M=0.71, S D=0.76$ ). A higher score on the family cumulative risk scale indicated a more problematic family environment (range $=0-3, M=0.65, S D=0.82$ ), whereas a higher promotive score represented a more positive family environment (range $=0-4, M=1.03, S D=1.04$ ). Finally, a high score on the school cumulative risk scale indicated a negatively perceived school environment (range $=0-2, M=$ $0.49, S D=0.64$ ), and on the promotive scale it indicated a positively perceived school environment (range $=0-1, M=$ $0.19, S D=0.40$ ).

\section{Risk Effects}

To examine the effects of promotive scales relative to those of risk scales, we conducted a stepwise MNLM analysis. Our baseline model (not shown) included gender and SES. Both variables showed significant effects on nondelinquents and serious delinquents. Being a male decreased the likelihood of being a non-delinquent $(-9.3 \%$; $p<0.01)$ and increased the likelihood of being a serious delinquent $(+8.5 \% ; p<0.01)$. High SES increased the likelihood of being a non-delinquent $(+5.1 \% ; p<0.05)$ and decreased the probability of being a serious delinquent $(-2.8 \% ; p<0.05)$. Low SES increased the likelihood of being a serious delinquent $(+5.2 \% ; p<0.01)$.

The cumulative risk scales were entered in the next step (see Table 3 ). The model fit improved significantly after adding the cumulative risk scales $\left(\Delta \chi^{2}(16,2,085)=61.56\right.$; $p<0.01)$. All three risk scales showed significant effects, but on different delinquent groups. Family risk decreased the likelihood of being a non-delinquent $(-5.0 \% ; p<0.01)$, and increased the likelihood of being a minor delinquent $(+4.2 \% ; p<0.01)$. Temperament and school risks increased the likelihood of being a serious delinquent. Again, it can be seen that the sum of each row with marginal effects in Table 3 is zero.

\section{Promotive Effects}

In the second step we included the cumulative promotive scales. The model fit improved significantly $\left(\Delta \chi^{2}(16\right.$, $2,085)=47.34 ; p<0.01)$. The strongest direct promotive effects were found for temperament and family. A higher score on the promotive temperament scale increased the probability of being a non-delinquent $(+5.2 \% ; p<0.01)$ and decreased the likelihood of being a minor delinquent $(-3.1 \% ; p<0.05)$, or a serious delinquent $(-2.1 \% ; p<$ $0.05)$. Further, a higher score on the family scale increased the likelihood of being a non-delinquent $(+3.1 \% ; p<0.01)$, and decreased the likelihood of being a minor delinquent $(-2.1 \% ; p<0.05)$.

\section{Protective Effects}

In a third step, we entered interaction terms to examine the risk-buffering effect of cumulative promotive factors. We calculated interactions between domains, for example, an interaction between individual risk and protective family characteristics. None of these interaction effects was significant, so we did not include these in the final model.

\section{Delinquency at the Baseline}

Finally, we included delinquency at T1. The model improved significantly $\left(\Delta \chi^{2}(4,2,085)=227.98 ; p<0.01\right)$. As expected, strong effects on delinquency at T2 were found for previous delinquent behavior. Furthermore, the cumulative risk effect of temperament on being a serious delinquent remained, just as the cumulative promotive effects of temperament and family on being a nondelinquent.

\section{Promotive-Risk Domains: a Counter-Balancing Effect}

The MNLM analyses showed the relative effect of each cumulative risk or promotive score on the three groups of delinquents. We examined counter-balancing effects of promotive factors on risks across the three domains by calculating an overall cumulative promotive-risk scale. This scale includes the cumulative scores on all three domains. The promotive-risk scale combines all scores of an individual (risk and promotive) on each domain.

Figure 1 shows for each category on this overall scale the percentages of non-delinquents and serious delinquents. As can be seen in Fig. 1, the more risk and the fewer promotive domains, the higher the percentage of serious delinquents. The percentages for non-delinquents show an 


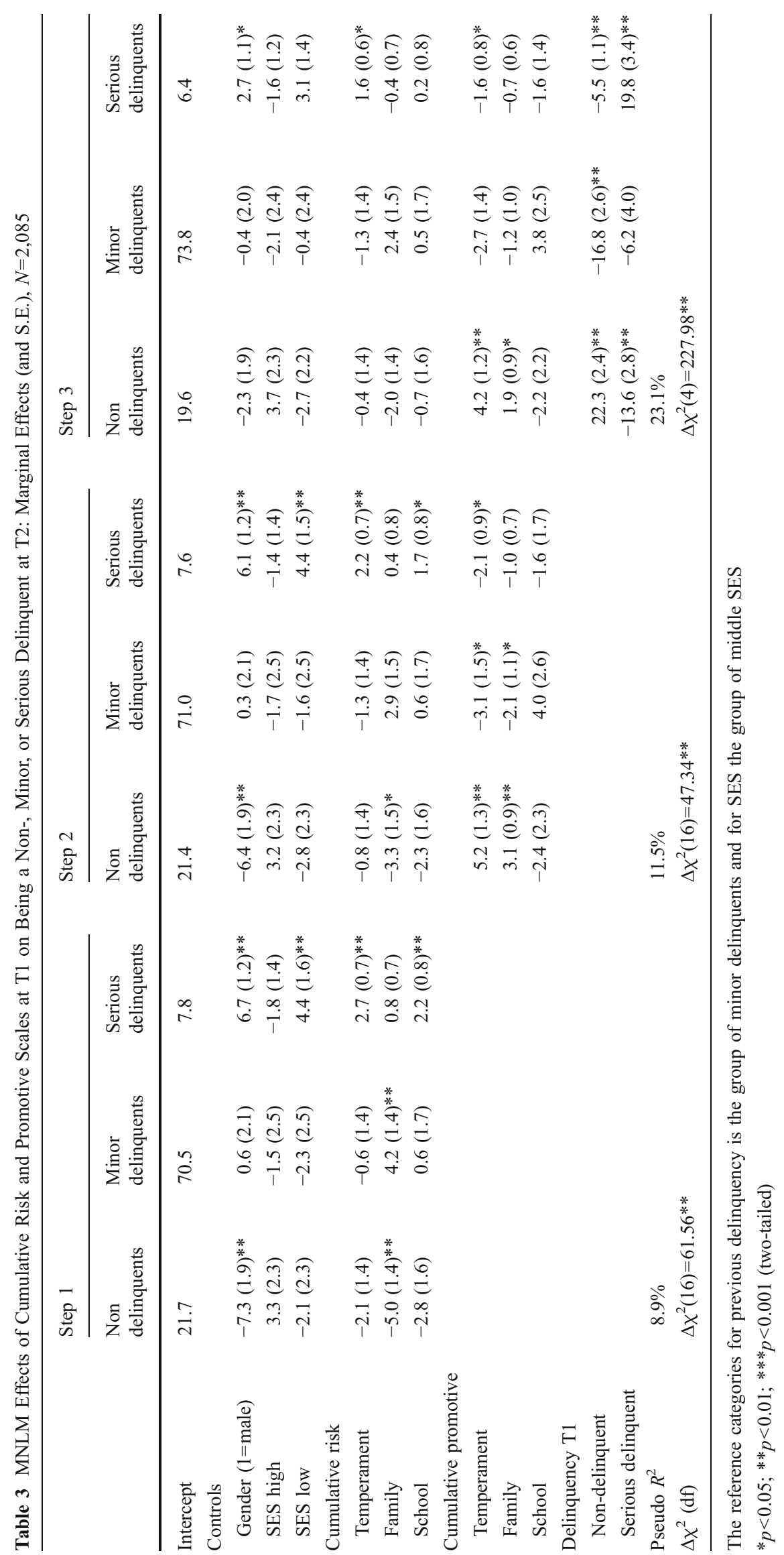


Fig. 1 From more promotive domains to more risk domains: a decrease of non-delinquents and an increase of serious delinquents (Shown is the overall cumulative promotive-risk scale. A low score indicates promotive effects on the three domains, a high score indicates risk scores on the domains. For each column the percentage of non- and serious delinquents are shown (not shown are the minor-delinquents))

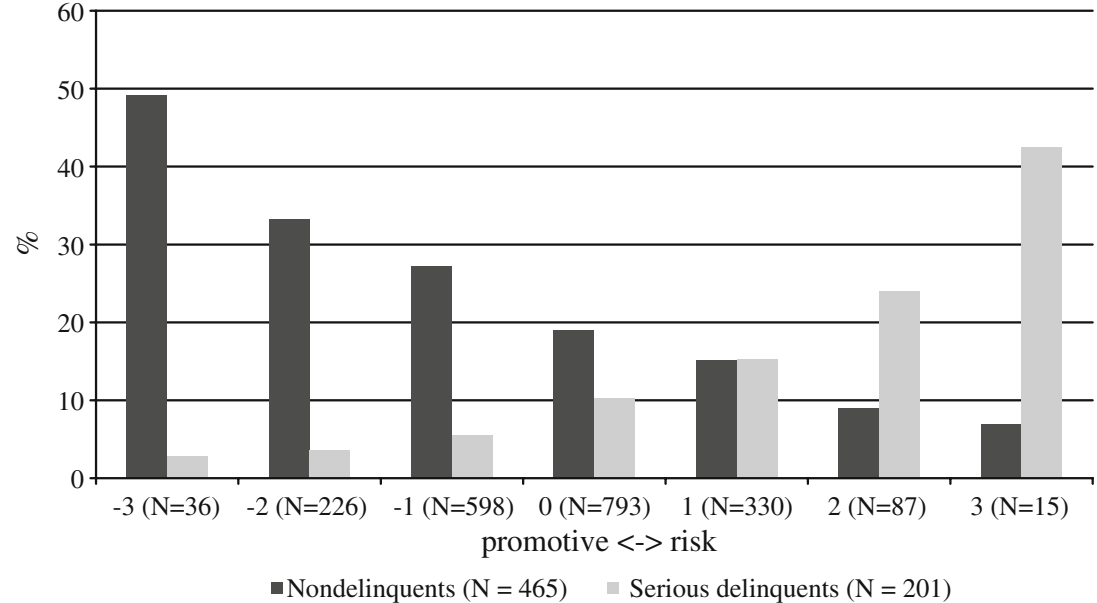

We extended previous research by focusing on risk and promotive effects in a general population sample on different levels of delinquency. In addition to previous research, we found that the bipolar effects are limited to the extreme poles of delinquency and generally do not account for the minor delinquents. For example, low effortful control, high surgency, high frustration, high parental stress and low academic performance increased the likelihood of serious delinquents, but had no effect on minor delinquents. On the other pole high effortful control, low surgency, low parental stress and low academic performance increased the probability of non-delinquents, and decreased the likelihood of serious delinquents, but had again no effect on minor delinquents. One explanation for the absent effects on minor delinquents can be that we did not include peer delinquency, which is an important predictor of (minor) delinquency (Farrington 2003).

Secondly, we examined the cumulative effects of risk and promotive summary scales on delinquency by using a risk, compensatory, and protective model. Our findings are in line with a cumulative risk hypothesis (see, e.g. Herrenkohl et al. 2001; Rutter 1987, 2003) that states that children exposed to multiple risks are more likely than others to engage in serious delinquency in adolescence. We found that a more difficult temperament, and a more negatively perceived school environment in preadolescence increased the probability of being a serious delinquent in early adolescence. After controlling for previous delinquency only the effect of a difficult temperament on being a serious delinquent remained.

In line with other studies (e.g., Dekovic 1999; Fergusson et al. 2007; Stouthamer-Loeber et al. 2002; Ostaszewski and Zimmerman 2006), we also found main effects of cumulative promotive scales on suppressing delinquency regardless of risk. An accumulation of promotive effects decreased the likelihood of being a serious delinquent, again with the strongest effect for temperament. Regardless of risks and 
controls, an easier temperament decreased the likelihood of being a serious delinquent. These results are in line with a compensatory model (Garmezy et al. 1984; Luthar et al. 2000; Stouthamer-Loeber et al. 2002; Zimmerman et al. 2006). The findings show additive effects of risk and promotive domains on being a serious delinquent and emphasize that cumulative promotive domains can counterbalance risk domains on being a serious delinquent (Pollard et al. 1999; Stouthamer-Loeber et al. 2002).

Contrary to our expectations, we did not find riskbuffering effects of cumulative promotive scales on the likelihood of being a serious delinquent. Thus, our results do not support a protective model for being a serious delinquent (Garmezy et al. 1984; Rutter 1987). An explanation for this can be that the interaction effects of promotive factors (the protective model) can only be found in high risk samples (Rutter 1987), and not in general population samples.

Our study showed similar effects of cumulative risk and promotive factors on non-delinquents. An easier temperament is associated with being a non-delinquent, regardless of risks and controls. Furthermore, a more supportive family environment relates to non-delinquents. These findings indicate that the most important factors during preadolescence for non-delinquents are situated in the individual and family domain, which corresponds to a developmental ecological model (Loeber et al. 2008; Sameroff et al. 1998). These findings are again in line with a compensatory model: The more promotive domains in the relative absence of risk domains relates to an increased percentage of non-delinquents.

Compared to previous studies on risk and promotive effects on delinquency, this study has major strengths, such as a longitudinal general population sample, a large number of participants, and the use of standardized measures. Another strength is that we mostly relied on multiple informant measures in order to give a more valid estimation of the associations as opposed to using single informant measures.

Some limitations should be mentioned. In order to examine the risk and promotive effects on different levels of delinquency, we trichotimized delinquency and the independent variables. According to Farrington and Loeber (2000) categorizing variables makes the interpretation of the results easier. However, these categorizations can be susceptible to misclassification and may have led to loss of information that can result in less significant relations with the delinquency groups than if we had used continuous variables. On the other hand Farrington and Loeber (2000) also showed that categorizing has little effect on conclusions about the relative importance of explanatory variables. Another limitation, as said before, is that peer delinquency is not included in our analyses.
In conclusion, we found that factors with regard to temperament, family, and school characteristics functioned both as risk factors for the likelihood of being a serious delinquent and as promotive factors for being a nondelinquent. In particular a more difficult temperament increased the chance on being a serious delinquent over time, whereas an easier temperament suppressed the likelihood of being a serious delinquent and promoted the probability of being a non-delinquent over time. We also found that promotive and risk domains on delinquency counterbalance each other. The aim of preventions and interventions for serious delinquency in early adolescence should be to reduce risk and stimulate promotive factors in multiple domains (compare Veenstra et al. 2009). In line with a developmental ecological perspective on delinquency (Loeber et al. 2008), we found promotive factors in the individual and family domain in preadolescence to increase the likelihood of being a non-delinquent and decrease the likelihood of being a serious delinquent, regardless of risks. This means that if risks are not known or hard to change, a focus on multiple promotive factors in different domains can reduce delinquency.

Open Access This article is distributed under the terms of the Creative Commons Attribution Noncommercial License which permits any noncommercial use, distribution, and reproduction in any medium, provided the original author(s) and source are credited.

\section{References}

Achenbach, T. M. (1987). Child-adolescent behavioral and emotional problems: implications of cross-informant correlations for situational specificity. Psychological Bulletin, 101, 212-232.

Achenbach, T. M. (1991a). Manual for the youth self-report and 1991 profile. Burlington: University of Vermont.

Achenbach, T. M. (1991b). Manual for the child behavior checklist 04-18 and 1991 profile. Burlington: University of Vermont.

Aiken, L. S., \& West, S. G. (1992). Multiple regression. Testing and interpreting interactions. Newbury Park: Sage.

Allison, P. D. (2002). Missing data. Thousand Oaks: Sage.

Borooah, V. K. (2002). Logit and probit. Ordered and multinomial models. Thousand Oaks: Sage.

Burke, W. T., \& Abidin, R. R. (1980). Parenting stress index (PSI): A family system assessment approach. In R. Abidin (Ed.), Parent education and intervention handbook (pp. 516-527). Springfield: Thomas.

Condly, S. J. (2006). Resilience in children: a review of literature with implications for education. Urban Education, 41, 211-236.

Dekovic, M. (1999). Risk and protective factors in the development of problem behavior during adolescence. Journal of Youth and Adolescence, 28, 667-685.

De Winter, A. F., Veenstra, R., Brunnekreef, J. A., Verhulst, F. C., \& Ormel, J. (2005). Evaluation of non response bias in mental health determinants and outcomes in a large sample of preadolescents. European Journal of Epidemiology, 20, 173-181. 
Epstein, N. B., Baldwin, L. M., \& Bishop, D. S. (1983). The McMaster family assessment device. Journal of Marital and Family Therapy, 9, 171-180.

Farrington, D. P. (2003). Developmental and life-course criminology: key theoretical and empirical issues. Criminology, 41, 221-256.

Farrington, D. P., \& Loeber, R. (2000). Some benefits of dichotomization in psychiatric and criminological research. Criminal Behavior and Mental Health, 10, 100-122.

Farrington, D. P., Loeber, R., Jolliffe, D., \& Pardini, D. A. (2008). Promotive and risk processes at different life stages. In R. Loeber, D. P. Farrington, M. Stouthamer-Loeber, \& H. Raskin White (Eds.), Violence and serious theft. Development and prediction from childhood to adulthood (pp. 169-230). New York: Routledge.

Fergus, S., \& Zimmerman, M. A. (2005). Adolescent resilience: a framework for understanding healthy development in the face of risk. Annual Review of Public Health, 26, 399-419.

Fergusson, D. M., \& Lynskey, M. T. (1996). Adolescent resiliency to family adversity116. Journal of Child Psychology and Psychiatry, 37, 281-292.

Fergusson, D. M., Vitaro, F., Wanner, B., \& Brendgen, M. (2007). Protective and compensatory factors mitigating the influence of deviant friends on delinquent behaviors during early adolescence. Journal of Adolescence, 30, 33-50.

Ganzeboom, H. B. G., \& Treiman, D. J. (1996). Internationally comparable measures of occupational status for the 1988 International Standard Classification of Occupations. Social Science Research, 25, 201-239.

Garmezy, N., Masten, A. S., \& Tellegen, A. (1984). The study of stress and competence in children: a building block for developmental psychopathology. Child Development, 55, 97-111.

Henry, B., Caspi, A., Moffitt, T. E., \& Silva, P. A. (1996). Temperamental and familial predictors of violent and nonviolent criminal convictions: age 3 to age 18109. Developmental Psychology, 32, 614-623.

Herrenkohl, T. I., Guo, H., Kosterman, R., Hawkins, J. D., Catalano, R. F., \& Smith, B. H. (2001). Early adolescent predictors of youth violence as mediators of childhood risks. Journal of Early Adolescence, 21, 447-469.

Herrenkohl, T. I., Hill, K. G., Chung, I. J., Guo, J., Abbott, R. D., \& Hawkins, J. D. (2003). Protective factors against serious violent behavior in adolescence: a prospective study of aggressive children. Social Work Research, 27, 179-191.

Hoeve, M., Blokland, A., Dubas, J. S., Loeber, R., Gerris, J. R. M., \& Van der Laan, P. H. (2008). Trajectories of delinquency and parenting styles. Journal of Abnormal Child Psychology, 36, 223-235.

Hoeve, M., Dubas, J. S., Eichelsheim, V. I., Van der Laan, P. H., Smeenk, W., \& Stams, G. J. (2009). The relationship between parenting and delinquency: a meta-analysis. Journal of Abnormal Child Psychology, 37, 749-775.

Hosmer, D. W., Hosmer, T., Le Cessie, S., \& Lemeshow, S. (1997). A comparison of goodness-of-fit tests for the logistic regression models. Statistics in Medicine, 16, 965-980.

Huisman, M. (2000). Imputation of missing item responses: some simple techniques. Quality \& Quantity, 34, 331-351.

Liao, T. F. (1994). Interpreting probability models. Logit, probit, and other generalized linear models. Thousand Oaks: Sage.

Lipsey, M. W., \& Derzon, J. H. (1998). Predictors of violent or serious delinquency in adolescence and early adulthood: A synthesis of longitudinal research. In R. Loeber \& D. P. Farrington (Eds.), Serious and violent juvenile offenders. Risk factors and successful interventions (pp. 86-106). London: Sage.

Loeber, R., Slot, N. W., \& Stouthamer-Loeber, M. (2008). A cumulative developmental model of risk and promotive factors.
In R. Loeber, N. W. Slot, P. H. Van der Laan, \& M. Hoeve (Eds.), Tomorrow's criminals. The development of child delinquency and effective interventions (pp. 133-161). Farnham: Ashgate.

Luthar, S. S., Cicchetti, D., \& Becker, B. (2000). The construct of resilience: a critical evaluation and guidelines for future work. Child Development, 71, 543-562.

Markus, M. T., Lindhout, I. E., Boer, F., Hoogendijk, T. H. G., \& Arrindell, W. A. (2003). Factors of perceived parental rearing styles: the EMBU-C examined in a sample of Dutch primary school children. Personality and Individual Differences, 34, 503519.

Moffitt, T. E., \& Silva, P. A. (1988). Self-reported delinquency results from an instrument for New-Zealand. Australian and New Zealand Journal of Criminology 21, 227-240.

Oldehinkel, A. J., Hartman, C. A., De Winter, A. F., Veenstra, R., \& Ormel, J. (2004). Temperament profiles associated with internalizing and externalizing problems in preadolescence. Development and Psychopathology, 16, 421-440.

Ormel, J. (2002). Social production function (SPF) theory as an heuristic for understanding developmental trajectories and outcomes. In L. Pulkkinen \& A. Caspi (Eds.), Paths to successful development. Personality in the life course (pp. 353-379). Cambridge: University Press.

Ormel, J., Lindenberg, S., Steverink, N., \& Vonkorff, M. (1997). Quality of life and social production functions: a framework for understanding health effects. Social Science \& Medicine, 45, 1051-1063.

Ostaszewski, K., \& Zimmerman, M. A. (2006). The effects of cumulative risks and promotive factors on urban adolescent alcohol and other drug use: a longitudinal study of resiliency. American Journal of Community Psychology, 38, 237-249.

Piquero, A. R., Farrington, D. P., \& Blumstein, A. (2003). The criminal career paradigm. In M. Tonry (Ed.), Crime \& justice (pp. 359-505). Chicago: University of Chicago.

Pollard, J. A., Hawkins, J. D., \& Arthur, M. W. (1999). Risk and protection: are both necessary to understand diverse behavioral outcomes in adolescence? Social Work Research, 23, 145-159.

Putnam, S. P., Ellis, L. K., \& Rothbart, M. K. (2001). The structure of temperament from infancy through adolescence. In A. Eliasz \& A. Angleitner (Eds.), Advances/proceedings in research on temperament (pp. 165-182). Berlin: Pabst Scientist.

Rothbart, M. K., Ahadi, S. A., \& Evans, D. E. (2000). Temperament and personality: origins and outcomes. Journal of Personality and Social Psychology, 78, 122-135.

Royston, P. (2004). Multiple imputation of missing values. Stata Journal, 4, 227-241.

Rutter, M. (1987). Psychosocial resilience and protective mechanisms. American Journal of Orthopsychiatry, 57, 316-331.

Rutter, M. (2003). Crucial paths from risk indicator to causal mechanism. In B. B. Lahey, T. E. Moffitt, \& A. Caspi (Eds.), Causes of conduct disorder and juvenile delinquency (pp. 3-26). New York: The Guilford.

Sameroff, A. J., Bartko, W. T., Baldwin, A., Baldwin, C., \& Seifer, R. (1998). Family and social influences on the development of child competence. In M. Lewis \& C. Feiring (Eds.), Families, risk, and competence (pp. 161-186). Mahwah: Erlbaum.

Sentse, M., Veenstra, R., Lindenberg, S., Verhulst, F. C., \& Ormel, J. (2009). Buffers and risks in temperament and family for early adolescent psychopathology: generic, conditional, or domainspecific effects? The TRAILS study. Developmental Psychology, $45,419-430$.

Smith, D. J. (2006). School experiences and delinquency. Ages 13 to 16. Edinburgh study of youth transitions and crime. Edinburgh: Centre for Law and Society, The University of Edinburgh.

Stouthamer-Loeber, M., Loeber, R., Farrington, D. P., Zhang, Q., Van Kammen, W. B., \& Maguin, E. (1993). The double edge of 
protective and risk factors for delinquency: interrelations and developmental patterns. Development and Psychopathology, 5, 683-701.

Stouthamer-Loeber, M., Loeber, R., Wei, E. H., Farrington, D. P., \& Wikström, P.-O. H. (2002). Risk and promotive effects in the explanation of persistent serious delinquency in boys. Journal of Consulting and Clinical Psychology, 70, 111-123.

Valois, R. F., MacDonald, J. M., Bretous, L., \& Fischer, M. A. (2002). Risk factors and behaviors associated with adolescent violence and aggression. American Journal of Health Behavior, 26, 454-464.

Vanderbilt-Adriance, E., \& Shaw, D. S. (2008a). Protective factors and the development of resilience in the context of neighborhood disadvantage. Journal of Abnormal Child Psychology, 36, 887-901.

Vanderbilt-Adriance, E., \& Shaw, D. S. (2008b). Conceptualizing and re-evaluating resilience across levels of risk, time, and domains of competence. Clinical Child and Family Psychology Review, $11,30-58$.
Van der Laan, A. M., \& Blom, M. (2006). Jeugddelinquentie: Risico's en Bescherming [Juvenile Delinquency: Risk and Promotive factors. Findings of the WODC Youth Delinquency Survey, 2005]. The Hague: WODC.

Veenstra, R., Lindenberg, S., Oldehinkel, A. J., De Winter, A. F., \& Ormel, J. (2006). Temperament, environment, and antisocial behavior in a population sample of preadolescent boys and girls. International Journal of Behavioral Development, $30,422-432$.

Veenstra, R., Lindenberg, S., Verhulst, F. C., \& Ormel, J. (2009). Childhood-limited versus persistent antisocial behavior: why do some recover and others do not? The TRAILS study. Journal of Early Adolescence, 29, 718-742.

Verhulst, F. C., \& Achenbach, T. M. (1995). Empirically based assessment and taxonomy of psychopathology: cross-cultural applications. European Child and AdolescentPsychiatry, 4, 6176. 